et al. (1964) found that after multiple passages the cells comprising the plasmacytoma could become considerably less differentiated, producing less paraprotein and growing faster. A few patients with obviously extensive rapidly growing myeloma similarly produce little or even no paraprotein, especially those who produce only Bence Jones protein.

In lymphosarcomata and in chronic lymphatic leukaemia, on the other hand, it seems to be the rule that when paraprotein production occurs it involves only a small percentage of the tumour cells. Mackay et al. (1957) thought that the presence of macroglobulinaemia in such cases was a secondary phenomenon, and arose from a side-line of mutated cells. The presence of more than one paraprotein has been demonstrated in three of our six patients with lymphomata-an incidence that is in marked contrast to our findings in myelomatosis, five out of a total of 320 patients showing more than one paraprotein. These findings also agree with those of Imhof et al. (1966), and support the hypothesis that paraprotein production in the tymphomata reflects unstable, mutating cell populations.

Paraproteins are also found in association with other malignant diseases, but their frequency is no greater than would be expected (Hällén, 1966). Moreover, their levels rarely correlate with the removal or progress of the cancer, and our own experience suggests that this largely occurs by chance.

\section{Summary}

Examination of blood and concentrated specimens of urine for paraproteins, together with the measurement of the other immunoglobulins, can have prognostic value in some groups of patients. In doubtful cases, following the paraprotein level can indicate within one to three years which cases are likely to show malignancy, though up to 10 years may be required before the diagnosis is certain, and up to 20 years where solitary lesions or only a trace of Bence Jones proteinuria are the presenting features.
This article would have been impossible without the participation and encouragement of the Medical Research Council and its Myeloma Trial Working-party. Many other patients have been referred from other physicians, particularly my colleagues at Hammersmith, who have kindly provided fuil details and follow-up data. I am indebted to the staff of the haematology and radiological departments. I would also like to thank Professor I. D. P. Wootton, Professor J. V. Dacie, and Dr. D. A. G. Galton for their guidance; Miss Hazel Gardner, Miss Susan Burtenshaw, and Mrs. Ann Kasler for their assistance; and Mr. K. B. Cooke for early guidance in immunoelectrophoresis.

\section{REFERENCES}

Axelsson, U., Bachmann, R., and Hällén, J. (1966). Acta med. scand., 179,235 .

Bachmar (1966) Scand. 7. ciin. Lab. Invest., 18, 273 and 280.

Barth W. F. Wochner, R. D. Waldmann, T. A., and Fahey, J. L. (1964). $\dddot{f}$. clin. Invest., 43, 1036.

Eerggard, I., and Edelman, G. M. (1963). Proc. nat. Acad. Sci. (Wash.), 49,330 .

Bradshaw, T. R. (1906). Brit. med. F., 2, 1442.

Drivsholm. A. (1964). Acta med. scand., 176, 257.

Fahey, J. L. (1965). f. Amer. med. Ass., 194, 255.

Gabuzda, T. G. (1962) 7. Lab. clin. Med. 59, 65.

Grabar, P. Fauvert, R., Burtin, P. and Hartmann, L. (1956). Rev franc. Etud. clin. biol., 1, 175 .

Hällén, J. (1966). Acta med. scand., Suppl. No. 462.

Harrison, W. (1966). Acta med. Scand., Suppl. 254

Hobbs, J. R. (1963). M.D. Thesis, London, p. 15.

- (1965). Nature (Lond.), 207, 292. (1966a). Sci. Basis Med. Ann. and Maatela, J. (1967). To be published.

- ct al. (1966). Lancet, 2, 614.

Imhof, J. W. Ballieux, R. E., Mul, N. A. J., and Poen, H. (1966). Acta med. scand., Suppl. No. 445 , p. 102.

Lowry O H and Hunter, T. H (1945) 7 biol. Chem. 159, 465.

MacKay, I. R., Taft, L. I., and Woods, E. F. (1957). Brit. med. f., 1, 561 .

Mechanik, N. (1926). Z. ges. Anat.; 79, 58.

Nathans, D., Fahey, J. L., and Potter, M. (1958). 7. exp. Med., 108 121

Nossal, G. J. V., and Mäkelä, O. (1962). Ann. Rev. Microbiol., 16, 53. Olesen, H. (1963). Scand. F. clin. Lab. Invest., 15, 497

Osserman E. F., Rifkind, R. A., Takatsuki, K., and Lawlor, D. P. (1964). Ann. N.Y. Acad. Sci., 113, 627.

Solomon A., Waldmann, T. A., and Fahey, J. L. (1963). F. Lab. clin. Med., 62, 1.

\title{
Lymphocyte Transformation and Chromosome Studies in Hodgkin's Disease
}

\author{
SYLVIA D. LAWLER,* M.D., M.C.PATH. ; C. R. PENTYCROSS, † M.B., B.CH. ; B. R. REEVES,
}

Brit. med. F., 1967, 3, 704-708

The circulating lymphocytes in Hodgkin's disease are assumed to be immunologically deficient because of the poor response shown by the patients in delayed hypersensitivity tests. There is some evidence that this anergy is present even in the earliest stages of the disease (Aisenberg, 1965). The question therefore arises whether the lymphocytes are also abnormal in any other respect.

One way of testing a population of lymphocytes is to study the responses to stimulation in vitro by phytohaemagglutinin. When normal lymphocytes are cultured with phytohaemagglutinin a high proportion are stimulated to divide, and a cell showing the associated morphological changes is said to have "transformed." Recent studies (Hersh and Oppenheim, 1965) have shown that the response of the lymphocytes in Hodgkin's disease is sometimes depressed. At least three factors may influence the response: the lymphocyte count, which is often very low; the stage of the disease at the time of investigation;

* Senior Lecturer.

+ Leukaemia Research Fellow.

$\ddagger$ Research Assistant.

Department of Clinical Research, Royal Marsden Hospital and Institute of Cancer Research, London S.W.3. and the effects attributable to radiation or chemotherapy. We have attempted to assess the relative importance of these factors.

Another way of characterizing a cell population is to determine the chromosome complement. Apart from a single case of Spiers and Baikie (1966), in which the peripheral blood lymphocytes were found to be normal, no information about the chromosomes of the circulating lymphocyte in Hodgkin's disease is available. There is no doubt that chromosomal abnormalities are detectable in lymph node material (Ricci et al., 1962 ; Spriggs and Boddington, 1962 ; Galan et al., 1963 ; Baker and Atkin, 1965 ; Miles et al., 1966 ; Spiers and Baikie, 1966). Various abnormalities have been described, including polyploid cells, presumed to represent SternbergReed cells, and anomalous chromosomes, particularly of the $\mathrm{E}$ group, in diploid cells.

\section{Materials and Methods}

Twenty cases have been studied. Some of the patients are the same as those investigated by Goldman and Hobbs (1967). The method used in the lymphocyte transformation tests is that 
described by Pentycross (1967) in which the final concentration of cells in culture is $10^{6} / \mathrm{ml}$. The phytohaemagglutinin cultures are harvested after 72 hours.

The chromosome and transformation studies were carried out on aliquots of the same blood samples. Microcultures using a slight modification of the method of Arakaki and Sparkes (1963) were often unsuccessful. Better results were obtained when suspensions of separated lymphocytes were used. The method was based on that of Moorhead et al. (1960), the polymorphs being removed by carbonyl iron (Carstairs, 1962). The preparations were fixed in 3:1 methyl alcohol and glacial acetic acid and the slides made by dropping a suspension in $45 \%$ acetic acid on to cold slides, which were then allowed to dry on a warm plate.

\section{Results}

\section{Response to Phytohaemagglutinin}

The percentage of transformed cells in the cultures from the patients ranged from less than 1 to 56 (transformation score). In our laboratory the score for normal people is $36-60 \%$. Many workers quote a higher score than this for normal lymphocytes. In our laboratory at least 4,000 cells are counted from each culture by scanning the slides in systematic strips. This scoring method gives a result representative of the entire cell population in the culture.

In assessing the cultured lymphocytes qualitatively, two types of anomalous cell, which are only rarely seen in normal controls, were found to occur with increased frequency. (1) Large, probably transformed, cells having a bizarre nuclear pattern and ragged pale cytoplasm. The nucleoli (almost invariably present) were amorphous, basophilic, and completely circular. (2) Cells the size of small and medium lymphocytes with amorphous nuclei.

In some instances, moreover, the majority of transformed cells satisfied only the morphological criteria (stippling of nuclear chromatin, visible nucleoli, large size, and cytoplasmic basophilia) to a limited degree.

Anomalous cells and poorly transformed ones were found predominantly in association with transformation scores of less than $30 \%$.

The patients have been arranged in the Table according to the transformation score. When a patient was tested a second time the higher score decided the position in the table.

The clinical staging (column 5 in table) was that of Peters (1950), modified by Kaplan (Karnofsky, 1966), as follows:

Stage 0: no detectable disease owing to excisional biopsy.

Stage I: disease localized to a single node and contiguous structures without systemic symptoms.

Stage II : disease limited by the diaphragm to the upper or lower half of the body, but at more than a single site.

Stage III: disease above and below the diaphragm.

Stage IV : disease demonstrated in any one of the following areas: bone marrow, pulmonary parenchyma, skin, gastrointestinal tract, or bone.

Stages II and III are subdivided into $A$ and B, with or without symptoms of generalized disease respectively.

These stages depend to a large extent on visible or palpable masses which do not necessarily relate to the total tumour bulk.

The information in the Table may be summarized as follows:

(a) There is some correlation between the percentage of transformed cells in the cultures of peripheral blood lymphocytes and the clinical staging. Thus the five patients in stages $0-I$ all had scores between 32 and $52 \%$. On the other hand, the scores for the 15 patients in stages II-IV ranged from less than $1 \%$ to $56 \%$, though all the patients with a score of less than $12 \%$ of transformed cells were staged at least as IIB.

(b) Age and length of history appear not to have influenced lymphocyte response to any significant degree. (c) Of the two untreated patients, one (Case 1) had a transformation score within normal limits, and the other (Case 12) a score just below normal. However, chemotherapy and recent local irradiation do not appear to have contributed to any extent to the depression of the lymphocyte response in this series.

(d) Some of the patients with lymphopenia (less than 1,500/ml.) had low transformation scores. Virtually all those with transformation scores of $12 \%$ or less were lymphopenic. However, a normal lymphocyte count was not necessarily associated with scores in the normal range.

(e) With one exception (Case 9), there was no significant difference in transformation score when tests were performed twice on any one patient.

\section{Chromosome Studies}

The results of the chromosome studies are given in column 9 of the Table. Only those cells which did not show features suggesting radiation damage were analysed in detail, but all cells appearing in the Table were scored for the presence of secondary constrictions in the paracentric third of the long arms of chromosome C9.

Mitotic yields were poor in patients with a low score in the transformation test. Good mitotic yields were obtained in the cultures in Cases $6(b)$ and 11, but only a few cells were of sufficient quality for analysis. This explains the discrepancy in these cases between the response of the lymphocytes to phytohaemagglutinin and the amount of data on the chromosomes.

In the series as a whole 19 cells out of 89 analysed were aneuploid. Twelve of these aneuploid cells were contributed by two patients (Cases 3 and 14). Rearranged modal cells were found in Case 3 but not in Case 14. Concurrently 89 cells were analysed from lymphocyte cultures of three normal indlviduals (covering the age range of patients in the study) and nine were found to be aneuploid.

In one untreated patient (Case 1) a hypomodal cell was found which contained a marker chromosome resembling a B-group chromosome with most of the short arms missing.

Some polyploid cells, not suitable for analysis, were seen in three patients (Cases 2, 3, and 11). The most likely cause of an increased number of polyploid cells is previous treatment with irradiation (Buckton et al., 1962); it is unlikely that these cells represent circulating Sternberg-Reed cells.

The criteria for assessing radiation damage were based on the data of Buckton et al. The aberrations seen in our material were fragments, dicentrics, and chromosomal rearrangements. Cells showing features of radiation damage were seen in two patients (Cases 13 and 14) who had been treated with vinblastine sulphate but not by irradiation. The possibility arises that the damage was due to the action of vinblastine in vivo, but we have been unable to produce chromosome breakage in normal lymphocyte cultures in vitro with vinblastine even with concentrations as high as $100 \mu \mathrm{g} . / \mathrm{ml}$. of culture medium.

In two patients (Cases 3 and 13) an apparent dicentric chromosome formed by an end-to-end association of two chromosomes was observed. In Fig. 1 the $D / F$ associated chromosome of Case 3 is shown; with this associated chromosome separated, the cell had a normal karyotype. In Case 13 (Fig. 2) the association was between $A 3$ and G21-22, but the cell showed evidence of radiation damage. This type of association is not generally recognized as a radiation effect, but it has been described in cultures of cells infected with virus (Moorhead and Saksela, 1963). Marker chromosomes composed of two chromosomes in an end-to-end association have been observed in testicular tumours from untreated patients (Martineau, 1967).

Secondary constrictions were seen in $11 \%$ of C 9 chromosomes in the normal controls previously mentioned. Among the patients, constrictions were present in $35 \%$ of available C9 chromosomes. An example of a constricted C9 chromosome 
Details of Patients

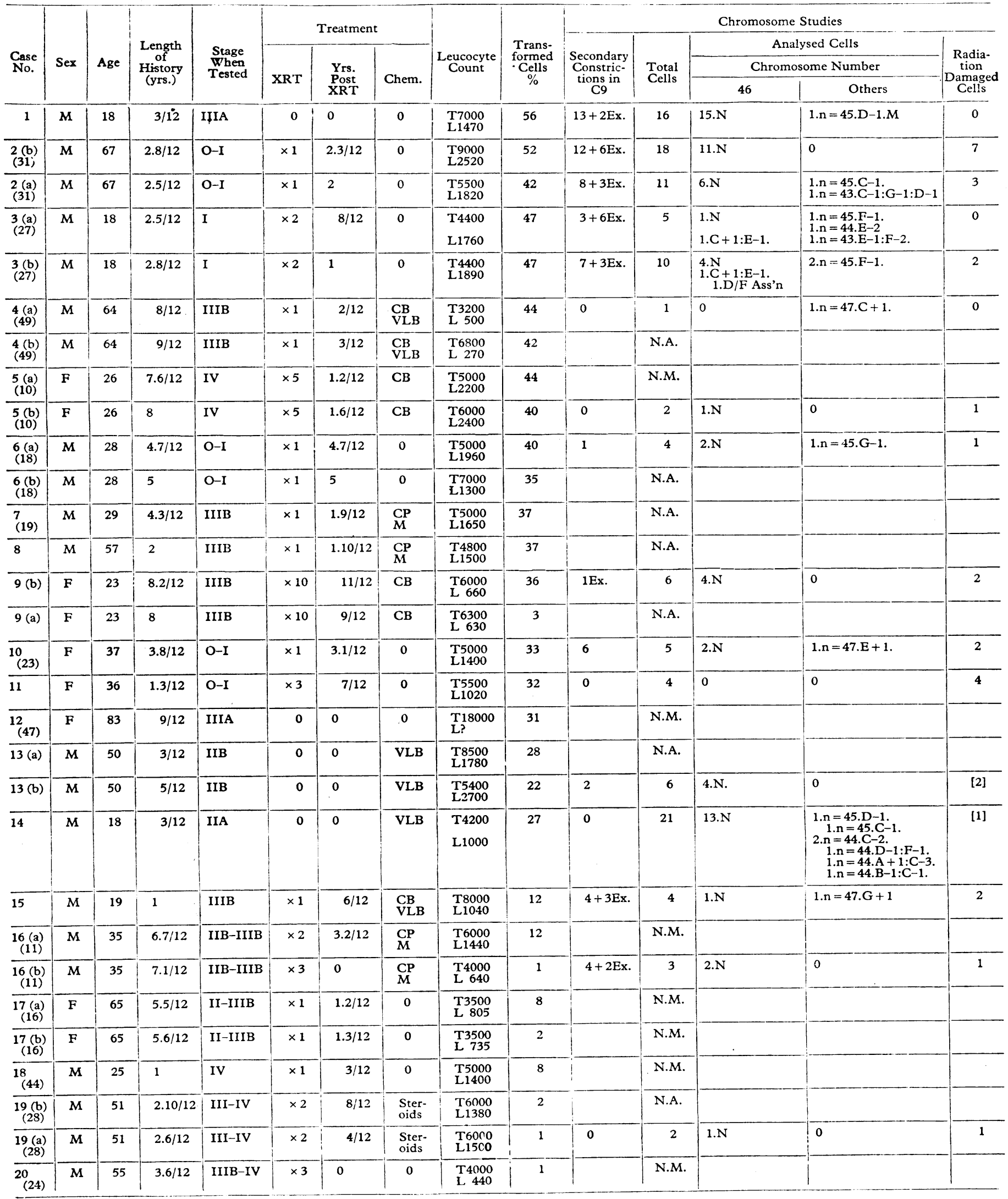

\section{Key to Table}

Column 1.- $($ ) $=$ Number in series of Goldman and Hobbs (1967). (a) = First test. (b) $=$ Second test. Column 6. $-M=$ Mustine hydrochloride. $C P=$ Cyclophosphamide. $V L B=$ Vinblastine sulphate. $C B=C$ lorambucil.

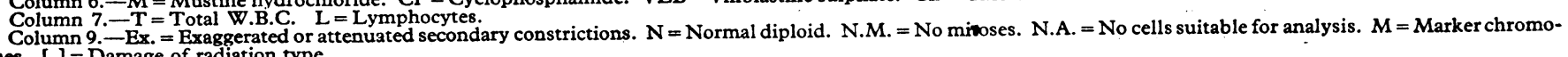
somes. [ ] = Damage of radiation type 
from a lymphocyte culture of a normal control, when using the same technique of culture, is shown in Fig. 3. Some of the constrictions obtained in the cultures of the patients were exaggerated and sometimes markedly attenuated, and in the Table these are indicated by the abbreviation Ex. An example of an attenuated constriction is shown in Fig. 4, and the tendency for acrocentric chromosomes to associate with such regions (Ferguson-Smith and Handmaker, 1963) is shown in Fig. 5. No exaggerated constrictions were seen in normal controls.

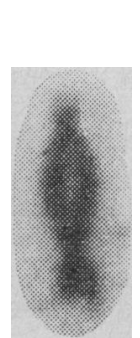

FIG. 1

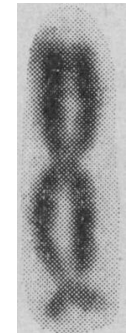

FIG. 2

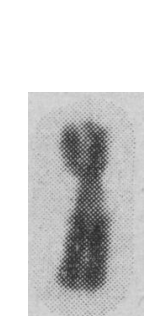

Frg. 3

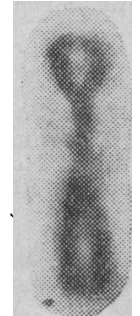

FIg. 4

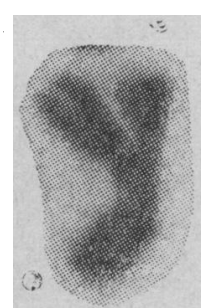

FIG. 5
Fig. 1.-D/F. Associated chromosome from Case 3. Fig. 2.-A3/G. Associated chromosome from Case 13. FIG. 3. - Constricted C9 chromo some from normal control lymphocyte culture. FrG. 4.-Attenuated constriction in a C9 chromosome from Case 3. FIG. 5.-D-chromosome associated with the exaggerated constriction in a $\mathrm{C} 9$ chromosome from Case 2.

\section{Discussion}

\section{Response to Phytohaemagglutinin}

There does seem to be a correlation between the clinical staging and the transformation scores. However, as noted already, the clinical staging may not precisely reflect the severity of the disease, since it depends on a visual assessment of the amount of disease present, which may bear no relation to total tumour bulk. A lymphangiogram, which is a useful test, especially for distinguishing stage II from stage III, was not always carried out on these patients.

The partial association between the lymphocyte count and the transformation score provides an interesting contrast to the situation existing in chronic lymphocyte leukaemia where there is a correlation between a high total lymphocyte count and a low transformation score (Hayhoe et al., 1967). In the latter disease it would seem that there is a large population of lymphocytes which are unresponsive to phytohaemagglutinin, and therapy preferentially eliminates these. It is possible that in Hodgkin's disease there is a progressive reduction in both the numbers of lymphocytes and their responsiveness.

Local irradiation does not seem to have influenced the transformation score. Millard (1965) established that large doses of irradiation, not localized, may depress lymphocyte transformation for variable periods after cessation of therapy.

There may possibly be other (as yet unknown) factors. Case 7 was tested when in stage IIIB, and in fact died within three months, and yet his cells transformed moderately well. Case 9 differed in no way clinically or haematologically on the two occasions she was tested, but the transformation score varied between 3 and $36 \%$.

\section{Chromosome Studies}

As might be expected when the response to phytohaemagglutinin is depressed, only few cells, if any, were available for analysis in patients with low scores in the transformation test. Suspension cultures proved more successful than microcultures. The failure of microcultures in lymphopenic patients can be attributed to the fact that an excessive number of red cells must be included in order to have an adequate number of lymphocytes.
In this series, more aneuploid cells were observed than were found in normal controls. This observation could be accounted for, at least in part, by radiation effects. There was no evidence for the circulation of a population of lymphocytes with abnormal chromosome complements. With the exception of the marker chromosome present in one cell of Case 1, no abnormal chromosomes resembling those observed in diploid cells obtained from lymph node material were seen.

In most cases the number of hypomodal cells was compatible with the assumption that they were randomly broken cells. The number of hypomodal cells in two patients (Cases 3 and 14) was significantly higher than in normal controls. This does not necessarily mean that a tendency to errors in division had produced the aneuploidy. Such a result could also be observed if the cells were more easily broken by the standard procedure than normal ones. The rearranged modal cells in Case 3 could not obviously be attributed to irradiation, but it is a possible cause, since Buckton et al. (1962) showed an increase in aneuploidy which sontinued for many years after $x$-ray treatment had been completed. In Case 14, treatment with vinblastine may have been the cause of increased aneuploidy. It is rare to find hypermodal cells in normal controls, but though one hypermodal sell was found in each of three patients the significance of this is difficult to assess because of the low mitotic yield.

The aumber of radiation-damaged cells observed was within the range described for lymphocytes in patients irradiated for other diseases.

The presence of prominent secondary constrictions in C9 chromosomes has been observed in lymph node material from patients with lymphomas (Miles et al., 1966). In this laboratory, cells from a node of a patient with Hodgkin's disease, additional to those in the series, showed constrictions in 16 $(38 \%)$ of the available C9 chromosomes when cultured with phytohatmagglutinin. Four of these constrictions were exaggerated.

This ceature of increased frequency and prominence of secondary constrictions in the chromosomes of lymphoid cells is not cestricted to Hodgkin's disease, since we have also observed it in parients with other malignant lymphomas and plasmocytomil. In assessing the significance of this observation certain facts bave to be taken into account. These constrictions can be observed in lymphocyte cultures from normal individuals with 3 lower frequency, but it is extremely rare to find them in the irtenuated form shown in Figs. 4 and 5. The frequency and the appearance of these constrictions can be altered in cultures of normal cells by varying the proportions of methyl alcohol ind acetic acid in the fixative (Saksela and Moorhead, 1962), but in the present study the fixative was maintained throughout at the standard concentration. Cells treated with SV 4) rirus in culture (Moorhead and Saksela, 1963) or with mitorxycin $C$ (Cohen and Shaw, 1964) or bromodeoxyuridine (Kaback et al., 1964) also show an increased number of secondary constrictions. The appearances of the attenuated constrictions seten in the present study resemble the effect produced by the aldition of mitomycin $C$ to in-vitro cultures of lymphocytes. In this context it is interesting to note that mitomycin $\mathbf{C}$, in causing chromosomal breakage in vitro, shows a preference for the areas of secondary constrictions. In this respect it differs trom the other agents that have a random effect, though some these may induce increased frequency of secondary constrictions.

The sccurrence of secondary constrictions is not restricted to $\mathrm{C} 9$ shromosomes, but in this study it is the quantitative increase and attenuation in this particular chromosome that is most nurable. The effect cannot be regarded as a specific one because it has been observed in patients with malignant lymphoma of different histological patterns and it is an exaggerated expression of a normal feature of the chromosomes. The enhancement of the secondary constriction in these diseased states is probably not due to treatment, since it cail be observed 
in untreated cases. The association between lympho-proliferative disorders and the prominence of these regions of the chromosomes which are peculiarly sensitive to alteration by the action of certain chemical agents may have some relevance to the choice of drugs to be used in treatment.

\section{Summary}

The characteristics of the circulating lymphocytes in Hodgkin's disease have been investigated in 20 patients. The methods used were (1) in vitro response to phytohaemagglutinin and (2) chromosome analysis.

Transformation Studies. - The percentage of the lymphocytes that transformed morphologically after stimulation with phytohaemagglutinin varied between less than 1 and 56 (normal controls $36-60 \%$ ). The depression of response was correlated to some extent with the severity of the disease. In some instances a low transformation score was associated with total lymphopenia. The depression of response did not appear to depend on current or previous treatment. It was concluded that the deficiency in response is one of the manifestations of the disease.

Chromosome Studies.-Mitotic yields were often low, but better results were obtained with suspension cultures than with microcultures. Most of the aneuploid cells, or cells with anomalous chromosomes, which we observed could be attributed to the effects of treatment. The frequency of radiation damage was within expected limits as compared with patients irradiated for other diseases. An increased frequency of constrictions in the C9 chromosome and the occasional exaggeration of this constriction was observed. This represents a modification of a feature present in normal cells and is by no means specific to Hodgkin's disease, since it has been observed in lymphoid cells in cases of other malignant lymphomas and in plasmocytoma.
The studies gave no indication of the circulation of a population of chromosomally abnormal lymphocytes, the majority of cells analysed having a normal chromosome complement.

We wish to thank Dr. L. Szur for permission to study his patients at the Hammersmith Hospital, and the consultant staff at the Royal Marsden Hospital for access to their patients ; Dr. J. M. Goldman and Dr. J. R. Hobbs for their co-operation; and Dr. D. A. G. Galton for his valuable criticism of the manuscript.

C. R.P. gratefully acknowledges a grant from the Leukaemia Research Fund Ltd. in support of his work.

Requests for reprints should be addressed to Dr. S. D. Lawler, Department of Clinical Research, Royal Marsden Hospital, London S.W.3.

REFERENCES

Aisenberg, A. C. (1965). Blood, 25, 1037.

Arakaki, D. T., and Sparkes, R. S. (1963). Cytogenetics, 2, 57.

Baker, M. C., and Atkin, N.B. (1965). Brit. med. 7., 1, 770

Buckton, K. E., Jacobs, P. A., Court Brown, W. M., and Doll, R. (1962). Lancet, 2, 676.

Carstairs, K. (1962). Ibid., 1, 829.

Cohen, M. M., and Shaw, M. W. (1964). F. Cell. Biol., 23, 386. Cohen, M. M., and Shaw, M. W. (1964). F. Cell. Biol., 23, 386.
Ferguson-Smith, M. A., and Handmaker, S. D. (1963). Ann. hum.

Galan, H. M., Lida, E. J., and Kleisner, E. H. (1963). Lancet, 1, 335. Goldman, J. M., and Hobbs, J. R. (1967). Immunology, 13, 421 .

Hayhoe, F. G.' J., Sinks, L. F., and Flemans, R. J. (1967). In The Lymphocyte in Immunology and Haemopoiesis, edited by J. M. Yoffey, p. 66. London.

Hersh, E. M., and Oppenheim, J. J. (1965). New Engl. f. Med., 273, 1006 .

Kaback, M. M., Saksela, E., and Mellman, W. J. (1964). Exp. Cell Res., 34, 182 .

Karnofsky, D. A. (1966). Cancer Res., 26, 1091.

Martineau, M. (1967). Lancet, 1, 386.

Miles, C. P., Geller, W., and O'Neill, F. (1966). Cancer, 19, 1103.

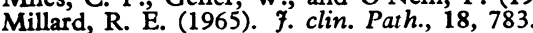

Moorhead, P. S., Nowell, P. C., Mellman, W. J., Battips, D. M., and Hungerford, D. A. (1960). 'Exp. Cell.'Res., 20, 613.

and Saksela, E. (1963). F. cell. comp. Physiol., 62, 57

Pentycross, C. R. (1967). F. clin. Path. In press.

Peters, M. V. (1950). Amer. F. Roentgenol., 63, 299.

Peters, M. V. (1950). Amer. F. Roentgenol., 63, 299. 2, 564 .

Saksela, E., and Moorhead, P. S. (1962). Cytogenetics, 1, 225.

Spiers, A. S. D., and Baikie, A. G. (1966). Lancet, 1, 506.

Spriggs, A. I., and Boddington, M. M. (1962). Ibid., 2, 153.

\title{
Mushroom-worker's Lung
}

\author{
ALEX SAKULA,* M.D., M.R.C.P.
}

[With Special Plate between Pages 708 and 709]

In recent vears the increased demand for mushrooms as a table delicacy has led to the development of intensive methods of cultivation in mushroom-growing farms. Many workers are at present involved in mushroom growing, and are therefore exposed to any potential hazard which might be associated with the process

Mushroom growers have themselves been aware of the occasional development of various symptoms during the course of their work, but the only medical report of these was by Bringhurst et al. (1959), who described a respiratory disease among 16 immigrant Puerto Ricans working in the "Chester" County area of Pennsylvania, where $90 \%$ of the mushrooms consumed in the United States are cultivated. No special reports of similar cases have appeared since then.

In this paper four cases are described of mushroom workers in Sussex (where $50 \%$ of English mushrooms are cultivated) who developed respiratory disorders thought to be related directly to their occupation.

- Consultant Physician, Redhill General Hospital, Surrey.

\section{Mushroom Cultivation}

The common edible mushroom, Agaricus hortensis (or Psalliota bispora), is grown on natural compost, consisting of a mixture of wheat straw and fresh horse manure, which is allowed to become partially decomposed or composted. This composting takes place in two phases.

In phase 1, carried on outdoors, stacks of compost are exposed to the atmosphere for three weeks. In phase 2 the compost is placed on to large wooden trays, introduced into closed chambers, and subjected for several days to a peak heat of 55$60^{\circ} \mathrm{C}$., and $100 \%$ humidity, produced by blowing live steam into the chambers. This pasteurizing process kills off the pests and organisms which would interfere with the growth of the mushrooms. Various thermotolerant and thermophilic actinomycetes find the conditions of both phases of the composting process conducive to their growth.

The compost is then cooled to $25^{\circ} \mathrm{C}$., and planted with specially prepared mushroom mycelium grown on manure or grain (known as spawn). This spawning process is usually 